\title{
Loss of $\delta-\mathrm{GABA}_{\mathrm{A}}$ receptor-mediated tonic currents in the adult prelimbic cortex following adolescent alcohol exposure
}

\author{
Samuel W Centanni ${ }^{1}$, Elizabeth J. Burnett ${ }^{1}$, Heather Trantham-Davidson ${ }^{1}$, and L. Judson \\ Chandler $^{1}$ \\ ${ }^{1}$ Department of Neuroscience, Medical University of South Carolina, 67 President St, Charleston, \\ SC 29425
}

\begin{abstract}
Delayed maturation of the adolescent prefrontal cortex (PFC) may render it particularly vulnerable to insults, including those associated with drugs of abuse. Using a rat model of binge alcohol exposure, the present study examined the effect of adolescent intermittent ethanol (AIE) exposure during post-natal days (PD) 28-42 on GABAergic neurotransmission in the prelimbic cortex (PrLC). In control rats, patch-clamp electrophysiology in acute slices obtained at different postnatal ages revealed a developmental increase in the $\mathrm{GABA}_{\mathrm{A}}$ receptor-mediated tonic current in layer $\mathrm{V}$ pyramidal neurons but no change in layers II/III when measured in the adult. In slices from AIE exposed rats, the amplitude of the tonic current was significantly reduced compared to controls when tested at PD 45, 60 and 90-120. This AIE-induced reduction in tonic current was found to reflect attenuation of currents mediated by $\delta$-subunit containing receptors. Consistent with this, facilitation of the tonic current by bath application of either ethanol or allopregnanolone was attenuated in slices from AIE exposed adult rats compared to control rats. However, expression of this facilitation as a percent of the amplitude of the total current mediated by $\delta-\mathrm{GABA}_{\mathrm{A}}$ receptors revealed that AIE did not alter their sensitivity to either agonist. Lastly, immunohistochemistry and Western blot analysis revealed no change in the expression of $\delta-\mathrm{GABA}_{\mathrm{A}}$ subunits or their surface expression. Taken together, these studies reveal that AIE exposure results in persistent deficits in $\delta-\mathrm{GABA}_{\mathrm{A}}$ tonic currents in the adult PrL-C that may contribute to deficits in decision-making and behavioral control in adulthood.
\end{abstract}

\section{Keywords}

adolescence; alcohol; $\mathrm{GABA}_{\mathrm{A}}$ receptors; prefrontal cortex; pyramidal; tonic current

Correspondence should be addressed to: L. Judson Chandler, Department of Neuroscience, Medical University of South Carolina, Charleston, SC 29425, Phone: 843-792-5224, chandj@ musc.edu.

Disclosure/Conflict of Interest: The authors have no conflict of interests to declare.

Authors Contribution: SWC, HTD, and LJC were responsible for the concept and design of the study. SWC, EJB and HTD acquired the data. SWC, EJB, HTD and LJC were responsible for writing the manuscript, and all authors critically reviewed the content and approved the final version for publication. 


\section{Introduction}

Inhibitory neurotransmission critically regulates neuronal function and behavioral control. In the brain, the majority of inhibition is mediated by activation of the A-type of $\gamma$ aminobutyric acid receptors $\left(G_{A B A} R\right)$. Stimulation of $G_{A B A}$ Rs generates two forms of neurotransmission: a rapidly desensitizing phasic current that is principally associated with activation of synaptic receptors, and a non-desensitizing tonic current that is associated with activation of extrasynaptic receptors [for review see (Farrant and Nusser, 2005)].

Accumulating evidence indicates that the tonic current is especially important in modulating neurodevelopment and plasticity (Hines et al., 2012). Consistent with this, alterations in tonic $\mathrm{GABA}_{\mathrm{A}} \mathrm{R}$ currents have been implicated in diverse neuropathological conditions such as autism, epilepsy, addiction, and various psychiatric disorders (Akbarian et al., 1995; BenAri et al., 2007; Cramer et al., 2010; Hashimoto et al., 2008; LeBlanc and Fagiolini, 2011; Tabuchi et al., 2007; Wang and Kriegstein, 2009).

Adolescence is a unique period of neurodevelopment that is characterized by changes in both brain structure and function. It is also a period of increased risk-taking and impulsive decision-making that is thought to relate, at least in part, to the delayed maturation of the executive function of the prefrontal cortex (PFC) (Casey and Jones, 2010). It is widely believed that the enhanced ability of the adolescent PFC to undergo experience-dependent changes renders it particularly vulnerable to adverse environmental insults such as that associated with binge consumption of alcohol. Alcohol consumption during adolescence typically occurs in excessive binge-like patterns that often result in dangerous levels of intoxication that may adversely affect brain development and function. Consistent with this, there is increasing evidence that adolescent alcohol abuse results in deficits in cognitive function mediated by the PFC that persist well into adulthood, Given the high prevalence of adolescent alcohol abuse worldwide, gaining greater insight into how adolescent alcohol abuse impacts on the adult behavior and decision-making is of high clinical significance.

A number of studies in both humans and animals have reported that adolescent alcohol exposure results in long-lasting deficits in the executive function of the PFC (De Bellis et al., 2005; Gass et al., 2014; Spear, 2000; Squeglia et al., 2014; Squeglia et al., 2009). However, the cellular mechanisms that underlie these cognitive deficits have been have received little attention and are poorly understood. In light of the critical role that tonic $\mathrm{GABA}_{\mathrm{A}}$ currents play in neurodevelopment and neuroplasticity and the high sensitivity of the developing PFC to environmental insults, the present study investigated the impact of binge-like adolescent alcohol exposure on GABAergic neurotransmission in the PFC.

\section{Materials and Methods}

\section{Animals and Adolescent Ethanol Exposure}

Long-Evans rats were obtained from our in-house breeding colony (breeder stocks obtained from Charles River). All experimental procedures were conducted with the approval of the Institutional Animal Care and Use Committee at the Medical University of South Carolina, and were within guidelines set forth by the National Research Council's Guideline for the Care and Use of Mammals in Neuroscience and Behavioral Research (2003). 
The adolescent intermittent ethanol (AIE) exposure model involved intermittent binge-like exposure to alcohol by vapor inhalation as previously described (Gass et al., 2014). Unless otherwise noted, all studies were conducted in male rats and a litter size consisted of at least 4 males in order to be included in the study. Upon weaning at PD 21, the pups were divided into control and experimental groups and pair-housed as littermates in standard polycarbonate cages for the duration of the study. The animal colony room was maintained on a 12:12 reverse light-dark cycle with lights extinguished at 08:00. AIE exposure occurred during early to middle adolescence (PD28-42) and involved 4 cycles of 2 consecutive episodes of alcohol vapor inhalation, with each episode consisting of $14 \mathrm{hrs}$ in the vapor chambers (18:00-08:00) followed by $10 \mathrm{hrs}$ out of the chambers (08:00-18:00). Rats were exposed to alcohol vapor or air (control) on PD28 \& 29 (cycle 1), PD32 \& 33 (cycle 2), PD36 \& 37 (cycle 3), and PD40 \& 41 (cycle 4). Intoxication levels were determined at the end of each $14 \mathrm{hr}$ period of exposure using a 5-point behavioral intoxication rating scale (Supplemental Figure S1A). Tail vein blood was collected from the alcohol exposed but not Air exposed rats at the end of each 2-day cycle and used for determination of blood ethanol concentration (Supplemental Figure S1B).

\section{Electrophysiological Recordings}

Recordings were performed using acute brain slices (300 $\mu \mathrm{m}$ thickness) containing the prelimbic cortex (PrL-C) obtained at different ages as previously described (Gass et al., 2014; Trantham-Davidson et al., 2014). Unless otherwise specified, all recordings were obtained from pyramidal neurons in layer $\mathrm{V}$ that were identified visually with infrareddifferential interference contrast optics and video-microscopy as previously described. For all experiments, dl-2-amino-5-phosphonovalerate (dl-APV, $50 \mu \mathrm{M})$ and 6-cyano-2,3dihydroxy-7-nitro-quinoxaline (CNQX, $10 \mu \mathrm{M})$ were added to the recording artificial cerebral spinal fluid (ACSF) to block $N$-methyl-D-aspartic acid (NMDA) and a-Amino-3hydroxy-5-methyl-4-isoxazolepropionic acid (AMPA) currents, respectively. IPSCs were evoked using a tungsten bipolar stimulating electrode placed in layer V within $200 \mu \mathrm{M}$ of the soma of the pyramidal neuron being recorded. Tonic $\mathrm{GABA}_{\mathrm{A}}$ Rs currents were isolated as previously described (Fleming et al., 2007) using standard pharmacological procedures to manipulate the holding current. Detailed information about electrophysiological recording methods is presented in the Supplemental Methods and Material.

\section{Western Blotting and Immunohistochemistry}

The expression of $\mathrm{GABA}_{\mathrm{A}} \mathrm{R}$ subunits in the PrL-C was examined using standard Western blotting and immunohistochemical procedures as previously described (Trantham-Davidson et al., 2014). Analysis of the surface expression of $\mathrm{GABA}_{A}$ Rs containing the $\delta$-subunit was also assayed as previously described (Grosshans et al., 2002). Detailed information about the blotting and immunohistochemistry methods is presented in the Supplemental Methods and Material. 


\section{Results}

\section{Expression of GABA $A$ Tonic Current in Layer V of the PrL-C is Developmentally Regulated}

The first set of studies examined the developmental changes in GABAergic

neurotransmission in layer $\mathrm{V}$ pyramidal neurons of the PrL-C using acute slice patch-clamp electrophysiology. A typical voltage clamp ( $-70 \mathrm{mV}$ clamp) recording (Figure 1A) consisted of a 15 min baseline period followed by 20 minutes of bath application of the $\mathrm{GABA}_{\mathrm{A}} \mathrm{R}$ antagonist picrotoxin $(100 \mu \mathrm{M})$ in order to determine the amount of tonic current. A cell was considered to have a tonic current if the change in holding current $\left(\mathrm{I}_{\mathrm{hold}}\right)$ in response to picrotoxin was greater than $5 \mathrm{pA}$. As shown in Figure 1B, both $\mathrm{GABA}_{\mathrm{A}} \mathrm{R}$ sIPSCs and $\mathrm{GABA}_{\mathrm{A}} \mathrm{R}$-mediated tonic currents were of similar amplitude when measured in slices obtained from rats across development and adulthood (age blocks = PD16-30, PD31-45, PD46-60, PD61-75, PD75-90, and >PD90). There was, however, a difference in the number of pyramidal neurons that exhibited a tonic current across development. As shown in Figure $1 \mathrm{C}$, the percentage of neurons that exhibited a change in holding current in response to picrotoxin was very low early in development ( $\sim 20 \%$ at PD16-45). This percentage progressively increased during the transition from adolescence to adulthood such that virtually all cells recorded in slices obtained from fully mature adults exhibited a picrotoxin sensitive tonic current $\left(\chi_{(5)}^{2}=19.6, p=0.002\right)$. In contrast to changes in the tonic current, all cells recorded from across all age groups exhibited similar sIPSC amplitude and frequency and thus, unlike the tonic current, there were no developmental changes in synaptic $\mathrm{GABA}_{\mathrm{A}} \mathrm{R}$ currents.

\section{Developmental emergence of the $\mathrm{GABA}_{A} R$ Tonic Current is Absent Following Adolescent Alcohol Exposure}

The next set of studies examined the effect of AIE exposure on both phasic and tonic GABAergic neurotransmission. As shown in Figure 2A-B, the frequency of the sIPSCs in control and AIE exposed adult rats was not significantly different $\left(\mathrm{t}_{(30)}=0.06, p=0.948\right)$, suggesting that AIE did not alter synaptic GABA release. Consistent with this, neither the paired-pulse ratio $\left(\mathrm{t}_{(16)}=0.96, p=0.352\right.$; Figure $2 \mathrm{C}$-D), nor the frequency of miniature IPSCs measured in the presence of tetrodotoxin (TTX, $1 \mu \mathrm{M}$ ) were affected by AIE exposure $\left(\mathrm{t}_{(15)}=0.33, p=0.744\right.$; Figure 2E-F). In contrast to the lack of an effect of AIE on presynaptic GABAergic neurotransmission, there was a significant reduction in the amplitude of the $\operatorname{sIPSC}\left(t_{(39)}=3.1, p=0.004\right)$ in slices from AIE exposed adult rats compared to controls (Figure 2A-B), which could potentially indicate an AIE-induced reduction in the postsynaptic response to the action potential generated synaptic release of GABA. However, this reduction in amplitude of sIPSCs was not reflected by a similar reduction in the amplitude of miniature IPSCs $\left(\mathrm{t}_{(15)}=1.05, p=0.310\right.$; Figure 2E-F). As supported by additional data shown in Supplemental Figure S2, this effect most likely reflects reduced activation of perisynaptic $\mathrm{GABA}_{\mathrm{A}} \mathrm{Rs}$ during spillover of action potential dependent synaptic release of GABA.

To determine whether AIE altered the tonic $\mathrm{GABA}_{\mathrm{A}} \mathrm{R}$ current, we next examined changes in holding current in response to bath application of picrotoxin in slices from rats of different developmental ages. A Gaussian distribution was fit to all-point histograms for each cell to 
determine the tonic current by subtracting the mean baseline $\mathrm{I}_{\text {hold }}$ from the mean $\mathrm{I}_{\text {hold }}$ after $100 \mu \mathrm{M}$ picrotoxin (Figure 3A,B). Consistent with the data presented in Figure 1, there were no significant differences in the amplitude of the tonic current as a function of age $\left(\mathrm{F}_{(3,22)}=\right.$ $0.74, p=0.538$; Figure 3C). However, as shown in Figure 3A-C, there was a significant difference in tonic current amplitude between control and AIE exposed rats $\left(\mathrm{F}_{(1,37)}=32.2, p\right.$ $<0.0001)$ at all three ages tested (PD45 \pm 3 days, $\mathrm{t}_{(9)}=2.7, p=0.025 ; \operatorname{PD} 60 \pm 3$ days, $\mathrm{t}_{(5.415)}=3.2, p=0.021 ;$ PD90 \pm 6 days, $\left.\mathrm{t}_{(8.421)}=3.2, p=0.012\right)$. Furthermore, AIE exposure also significantly attenuated tonic GABA currents in female rats $\left(\mathrm{t}_{(13)}=4.9, p=\right.$ 0.0003; Figure 3D), suggesting that the observed AIE-induced reduction in tonic GABA currents is not sex specific. These data demonstrate that AIE exposure results in the blunting of $\mathrm{GABA}_{\mathrm{A}} \mathrm{R}$-mediated tonic current in layer V PrL-C pyramidal neurons that persists well into adulthood.

One potential explanation for the observed AIE-induced reduction in tonic GABA current is a reduction in basal levels of extracellular GABA that could result in reduced tone on extrasynaptic $\mathrm{GABA}_{\mathrm{A}} \mathrm{Rs}$. To examine this possibility, we measured $\mathrm{GABA}_{\mathrm{A}} \mathrm{R}$ currents following bath application of the GABA reuptake inhibitor nipecotic acid $(500 \mu \mathrm{M})$. As shown in Figure 4A,B, this resulted in a very large hyperpolarizing current that presumably reflected activation of all GABARs (i.e. synaptic and extrasynaptic). To determine the contribution of the $\mathrm{GABA}_{\mathrm{A}}$ component of the nipecotic acid-induced current, picrotoxin was applied in combination with nipecotic acid. Once again, recordings taken from AIE exposed rats exhibited a significant reduction $\left(\mathrm{t}_{(13)}=2.3, p=0.041\right)$ in the amplitude of the $\mathrm{GABA}_{\mathrm{A}} \mathrm{R}$ tonic current suggesting that $\mathrm{AIE}$ induced attenuation of the tonic $\mathrm{GABA}_{\mathrm{A}} \mathrm{R}$ current was not the result of reduced levels of ambient GABA, and instead most likely reflects altered function and/or availability of extrasynaptic $\mathrm{GABA}_{\mathrm{A}} \mathrm{R}$.

Delta-subunit containing $\mathrm{GABA}_{\mathrm{A}} \mathrm{R}\left(\delta-\mathrm{GABA}_{\mathrm{A}} \mathrm{R}\right)$ are located almost exclusively in the extrasynaptic membrane, and together with a5-containing receptors, are thought to mediate the majority of the tonic current in layer V neurons (Drasbek and Jensen, 2006; Gill and Grace, 2014; Moss and Smart, 2001; Zheleznova et al., 2009). To determine whether the AIE-induced attenuation of tonic current reflected a reduction in $\delta-\mathrm{GABA}_{\mathrm{A}} \mathrm{R}$ currents, we used the $\delta$-GABA $\mathrm{A}_{\mathrm{A}} \mathrm{R}$ agonist 4,5,6,7-tetrahydroisoxazolo[5,4-c] pyridin-3-ol hydrochloride (THIP, $1 \mu \mathrm{M}$ ) to induce tonic currents in slices from control and AIE exposed rat. Gaussian distributions fit to all-point histograms for each cell were used to determine THIP-mediated current by subtracting the mean baseline $\mathrm{I}_{\text {hold }}$ from the mean $\mathrm{I}_{\text {hold }}$ after $1 \mu \mathrm{M}$ THIP (Figure 4A,B). In slices obtained from control rats, there was a progressive increase in the amplitude of THIP-mediated currents from PD28 to PD90 $\left(\mathrm{F}_{(3,22)}=4.4, p=0.015\right)$. This is in contrast to the studies shown in Figure $3 \mathrm{C}$ in which the amplitude of the $\mathrm{GABA}_{\mathrm{A}} \mathrm{R}$ (picrotoxin sensitive) tonic current did not change across development. Examination of the effect of AIE on the developmental time-course of $\delta-\mathrm{GABA}_{\mathrm{A}} \mathrm{R}$ currents revealed a significant effect of age in the control but not AIE treated rats. No between group differences were observed in the amplitude of $\delta-\mathrm{GABA}_{\mathrm{A}} \mathrm{R}$ tonic current in slices obtained shortly after the last cycle of ethanol exposure $\left(\mathrm{PD} 43-\mathrm{PD} 47 ; \mathrm{t}_{(8)}=0.28, \mathrm{p}=0.783\right.$ ) or at the onset of adulthood (PD58PD62; $\mathrm{t}_{(12)}=1.3, p=0.203$; Figure $5 \mathrm{C}$ ). In contrast, in fully mature adult AIE exposed rats, the amplitude of the $\delta-\mathrm{GABA}_{\mathrm{A}} \mathrm{R}$ current was attenuated compared to controls (PD90PD100; $\left.\mathrm{t}_{(17)}=2.2, p=0.041\right)$. In a separate set of experiments, bath application of THIP had 
no effect on sIPSC (amplitude $\left(\mathrm{F}_{(1,8)}=1.68, p=0.2310\right)$, frequency $\left(\mathrm{F}_{(1,8)}=0.26, p=\right.$ $0.625)$, rise $\left(\mathrm{F}_{(1,8)}=2.1, p=0.809\right)$ and decay $\left(\mathrm{F}_{(1,8)}=4.3, \mathrm{p}=0.073\right)$ times, or area $\left(\mathrm{F}_{(1,8)}\right.$ $=0.88, p=0.375)$, confirming the selectivity of THIP for extrasynaptic $\delta-\mathrm{GABA}_{\mathrm{A}}$ receptors (Supplemental Figure S3). These data indicate that early in development, the GABA tonic current is mediated by $\mathrm{GABA}_{\mathrm{A}}$ Rs that do not contain the $\delta$-subunit, whereas later in development and into adulthood a shift occurs toward increasing involvement of $\delta$ $\mathrm{GABA}_{\mathrm{A}} \mathrm{Rs}$. Importantly, this developmental emergence of the $\delta$-GABA $\mathrm{A}$-mediated tonic current is not observed following AIE exposure. Because the expression of $\mathrm{GABA}_{\mathrm{A}}$ receptors, specifically those that mediate the tonic current, have been shown to be hormonally regulated and can fluctuate throughout the estrous cycle (Sundstrom-Poromaa et al., 2002), we tested whether or not the effect of AIE on $\delta$-GABA $\mathrm{A}_{\mathrm{A}}$ receptor-mediated tonic currents was sex specific. Thus, THIP-mediated currents were measured in slices from control and AIE exposed adult female rats. As shown in Figure 5D, AIE significantly attenuated THIP-mediated currents in AIE exposed adult female rats $\left(\mathrm{t}_{(13)}=4.0, \mathrm{p}=0.002\right)$, indicating that the effect of AIE on the tonic $\mathrm{GABA}_{\mathrm{A}}$ current is not sex specific.

Recent studies have shown that not only are there developmental changes in $\mathrm{GABA}_{\mathrm{A}} \mathrm{R}$ subunit expression within the PFC but also that these changes are layer specific, with different cortical layers exhibiting unique developmental $\mathrm{GABA}_{\mathrm{A}} \mathrm{R}$ subunit profiles (Datta et al., 2014). We therefore examined the layer-specific effects of AIE on tonic $G_{A B A} R$ currents by recording from layer II/III pyramidal neurons in slices obtained from control and AIE exposed adult rats. As shown in Figure 5A \& B, slices obtained from both groups exhibited similar tonic current amplitudes $\left(\mathrm{t}_{(8)}=0.5, p=0.655\right)$. In addition, in experiments using THIP to activate $\delta-G A B A_{A} R$, AIE exposure had no effect on the amplitude of the tonic current $\left(\mathrm{t}_{(9)}=0.6, p=0.571\right.$; Figure $\left.6 \mathrm{~B}\right)$. Taken together, these data indicate that the AIE-induced reduction of the $\delta-\mathrm{GABA}_{\mathrm{A}} \mathrm{R}$ tonic current is specific to layer V PrL-C pyramidal neurons.

\section{Efficacy of Facilitation of the $\mathrm{GABA}_{A} R$ Tonic Current by Positive Allosteric Modulation is Reduced Following Adolescent Alcohol Exposure}

Acute ethanol enhances extrasynaptic $\delta$-GABA ${ }_{\mathrm{A}} \mathrm{R}$ tonic currents, and evidence suggests that this sensitivity to ethanol is imparted by the presence of the $\delta$-subunit (Breese et al., 2006; Wallner et al., 2003). To determine whether the AIE-induced reduction in $\delta$-subunit containing $\mathrm{GABA}_{\mathrm{A}} \mathrm{R}$-mediated tonic current was associated with a change in the acute sensitivity to ethanol, we next examined the effect of bath application of ethanol on the $\mathrm{GABA}_{\mathrm{A}} \mathrm{R}$ tonic current in layer V PrL-C slices obtained from control and AIE exposed adult rats. As expected, bath application of ethanol (10-100 mM) produced a dose-dependent facilitation of $\mathrm{I}_{\text {hold }}$ amplitude in slices from both control $\left(\mathrm{F}_{(1.8,10.7)}=33.1, \mathrm{p}<0.0001\right.$; Figure 7A,B $)$ and AIE exposed rats $\left(\mathrm{F}_{(1.5,10.5)}=21.51, p=0.0004\right)$. Post-hoc analysis revealed a significant reduction in $\mathrm{I}_{\text {hold }}$ in slices from AIE exposed rats at $50 \mathrm{mM}$ ethanol $\left(\mathrm{t}_{(14)}=2.5, \mathrm{p}=0.026\right)$ and $100 \mathrm{mM}$ ethanol $\left(\mathrm{t}_{(13)}=3.3, p=0.005\right)$, but not $10 \mathrm{mM}$ ethanol. The effect of ethanol was specific to the tonic GABA current, as ethanol had no effect on sIPSC kinetics (amplitude $\left(\mathrm{F}_{(3,36)}=0.57, p=0.637\right)$, frequency $\left(\mathrm{F}_{(3,36)}=0.39, p=0.395\right)$, rise $\left(\mathrm{F}_{(3,36)}=0.48, p=0.698\right)$ and decay $\left(\mathrm{F}_{(3,36)}=0.47, p=0.706\right)$ times, or area $\left(\mathrm{F}_{(3,36)}=\right.$ $0.70, p=0.560)$ ) at any dose (Supplemental Figure S4). As shown in Figure 7C, when the 
amplitude of the ethanol-facilitated current was expressed as a percentage of the amplitude of the average THIP-induced current (data from Figure 5), the percentage of the ethanolfacilitated increase was identical between control and AIE slices (Figure 7C).

Since $\mathrm{GABA}_{\mathrm{A}} \mathrm{R}$ tonic currents are also sensitive to neurosteroids, which like alcohol also appear to act as positive allosteric modulators of $\delta-G_{A B A} R$, we examined the effects of bath application of allopregnanolone $(0.1$ and $1.0 \mu \mathrm{M})$ on the tonic current. As expected, allopregnanolone enhanced $\mathrm{I}_{\text {hold }}$ in slices from control $\left(\mathrm{F}_{(1.2,11.08)}=36.5, p<0.0001\right)$ and AIE exposed $\left(\mathrm{F}_{(1.3,9.3)}=10.7, p<0.007\right)$ adult rats (Figure 7D,E). Similar to the effect of AIE on ethanol-facilitated tonic current, AIE also significantly attenuated the allopregnanolone-facilitated tonic current at both low and high concentrations $\left(0.1 \mu \mathrm{Mt}_{(13.6)}\right.$ $\left.=2.2, p=0.048 ; 1.0 \mu \mathrm{M} \mathrm{t}_{(16)}=2.25, p=0.039\right)$. Again, when expressed as a percentage of the average amplitude of THIP-activated current, no significant between group differences were observed (Figure 7F). While the above observations further demonstrate that AIE exposure results in reduced $\delta$-GABA $\mathrm{A}$ receptor-mediated tonic currents (observed as a reduced efficacy of both ethanol and allopregnanolone to facilitate channel conductance), the sensitivity of $\delta-\mathrm{GABA}_{\mathrm{A}}$ Rs to the facilitatory effect of either compound does not appear to be affected.

\section{Altered Expression of $\delta-G A B A_{A} R$ Subunits does not Underlie Attenuation of the Tonic Current}

One potential explanation for the AIE-induced attenuation of the tonic current is a reduction in the expression of $\delta-\mathrm{GABA}_{\mathrm{A}} \mathrm{Rs}$. To investigate this possibility, we obtained tissue punches of PrL-C from control and AIE-treated rats. Immunoblot analysis revealed no significant between group differences in the expression a 1, a 4, a5, $\delta$ or $\gamma 2 \mathrm{GABA}_{\mathrm{A}} \mathrm{R}$ subunits (Figure $8 \mathrm{~A})$. Since the reduction in the $\delta$-mediated tonic current may have resulted from in reduction in their surface expression that was offset by an increase in their internal expression, we also used the $\mathrm{BS}^{3}$ crosslinking procedure to specifically measure surface protein expression. Immunoblot analysis of the total and intracellular (non cross-linked) levels of the $\delta$-subunit again showed no significant difference between control and AIE exposed rats (Figure 8B). Because our slice electrophysiology studies revealed layer-specific effects of AIE on $\delta$ $\mathrm{GABA}_{\mathrm{A}} \mathrm{R}$-mediated tonic currents, it is possible that our immunoblot procedures were unable to detect any changes in $\mathrm{GABA}_{\mathrm{A}} \mathrm{R}$ subunit expression because the analysis was performed using tissue punches that contained all cortical layers within the PrL-C. We therefore performed a follow-up experiment using immunohistochemistry to examine layerspecific expression of the $\delta$-subunit in the PrL-C of both control and AIE exposed adult rats. Consistent with previous reports regarding $\delta$-subunit distribution (Pirker et al., 2000), immunohistochemistry revealed high levels of expression in the granule cell layer of the cerebellum, the dentate gyrus of the hippocampus and the anterodorsal and anteroventral nuclei of the thalamus (not shown), with lower levels of cortical expression (Figure 8C,D). Also in agreement with previous reports (Datta et al., 2014), we observed marked differences in $\delta$-subunit expression across the cortical layers, with superficial layers (I and II/III) exhibiting significantly higher levels of $\delta$-subunit expression compared to the deep layers (layer V/VI) $\left(\mathrm{F}_{(1,8)}=182.1, p<0.0001\right)$. However, consistent with our immunoblotting experiments, we did not observe a significant difference between control 
and AIE exposed rats in the staining intensity of the $\delta$-subunit in either the superficial or deep layers of the PrL-C.

\section{Discussion}

The present study demonstrates that layer $\mathrm{V}$ pyramidal neurons in the PrL-C of the rat undergo a striking increase in tonic $\mathrm{GABA}_{\mathrm{A}} \mathrm{R}$-mediated inhibition during adolescence. The developmental emergence of this current was observed as a change in the number of pyramidal neurons that expressed a measurable tonic $\mathrm{GABA}_{\mathrm{A}} \mathrm{R}$ current and a developmentdependent increase in current mediated by $\delta$-subunit containing $\mathrm{GABA}_{\mathrm{A}} \mathrm{Rs}$. Importantly, intermittent exposure to alcohol during the early to middle period of adolescence (PD28-42) resulted in a reduction in the amplitude of the tonic current. This reduction was observed shortly after the last period of AIE exposure (i.e., PD43-47) and persisted well into adulthood (i.e., >PD90). This effect was not sex specific as AIE exposure attenuated the tonic current to a similar extent in both male and female adult rats. In contrast to these observations in layer $\mathrm{V}$ pyramidal neurons, AIE exposure had no effect on the tonic $\mathrm{GABA}_{\mathrm{A}} \mathrm{R}$ current in layers II/III. Taken together, these observations demonstrate that AIE exposure results in a remarkably protracted and layer-specific deficit in tonic $\mathrm{GABA}_{\mathrm{A}} \mathrm{R}$ currents in PrL-C. The reduced inhibitory tone of layer $\mathrm{V}$ projection neurons may contribute to recent demonstrations of AIE-induced deficits in decision-making and behavioral control in adulthood (Boutros et al., 2014; Clark et al., 2012; Gass et al., 2014; Mejia-Toiber et al., 2014; Schindler et al., 2014).

GABA neurotransmission can operate in two modes. Phasic GABA currents produce IPSCs through classic synaptic processes that induce short bursts of inhibition (Farrant and Nusser, 2005). This mode of transmission provides spatial and temporal precision. In contrast, tonic GABA currents principally arise from ambient GABA in the extrasynaptic space that activates high affinity peri-/extrasynaptic $\mathrm{GABA}_{\mathrm{A}} \mathrm{Rs}$. The persistent activation of these receptors induces a strong inhibitory action on the cell by shunting the electrical signal. This mode of GABA neurotransmission is increasingly recognized as playing a critical role in the pathophysiology of various CNS and neurodevelopmental disorders (Egawa and Fukuda, 2013; Whissell et al., 2015). While tonic GABA currents have been observed in a number of brain regions, several studies have reported that acute slices from the mPFC lack a tonic GABA current (Drasbek and Jensen, 2006; Weitlauf and Woodward, 2008). It is important to note, however, that those observations were obtained in slices prepared from young animals. In the present study, we also observed that in slices from young rats (PD16-45), only a small percentage of neurons exhibited a measureable tonic $\mathrm{GABA}_{\mathrm{A}} \mathrm{R}$ current. However, as development progressed, the tonic current emerged such that in the fully mature adult (i.e., $>$ PD90), virtually all layer $\mathrm{V}$ pyramidal neurons recorded from exhibited a robust $\mathrm{GABA}_{\mathrm{A}} \mathrm{R}$ tonic current. This observation is consistent with recent findings in layer $\mathrm{V}$ of the dorsolateral PFC of the rhesus monkey that demonstrated developmental changes in $\mathrm{GABA}_{\mathrm{A}} \mathrm{R}$ subunits that are thought to contribute to the tonic current (i.e., $\delta, \gamma 2$, and, a5) (Datta et al., 2014). We also found that exposure of rats to intermittent ethanol during adolescence prevented subsequent developmental increases in the expression of the tonic current. Importantly, this AIE-induced reduction in tonic current was still observed in adulthood (e.g. >PD90) several months after the last period of exposure to alcohol. 
Therefore, AIE did not simply shift the time-course of the developmental trajectory of the tonic current and instead produced a long-lasting, potentially permanent, reduction in tonic GABAergic inhibition of layer V PrL-C pyramidal neurons.

A particularly interesting observation in the present study was that the AIE-induced reduction in tonic inhibition was layer specific, with attenuation of the tonic current in layer $\mathrm{V}$ but no change in layers II/III. Thus, protracted reduction in tonic inhibition associated with AIE exposure may be selective for pyramidal neurons of the PrL-C that provide output to subcortical structures. We, and others, have recently demonstrated that AIE exposure results in deficits in behavioral control in the adult that are consistent with PFC dysfunction (Gass et al., 2014; Spear, 2000; Squeglia et al., 2012). Although it is likely that alterations in the activity of other neurotransmitter and signaling systems contribute to these cognitive deficits, it is reasonable to suggest that the reduction in tonic inhibition we observed may be of particular importance to alterations in how the PFC processes information and directs behavior. Although the role that the tonic $\mathrm{GABA}_{\mathrm{A}} \mathrm{R}$ current plays in modulating network organization in the PFC is not clear, alterations in the level of tonic inhibition would be expected to significantly alter the input-output relationship and impact information processing within the $\mathrm{mPFC}$.

It has been previously reported that adult chronic alcohol exposure results in alterations in the expression of the $\delta$-subunit in the hippocampus (Cagetti et al., 2003; Liang et al., 2007; Liang et al., 2006), nucleus accumbens (Liang et al., 2014), and basolateral amygdala (Lindemeyer et al., 2014). Similarly, we recently reported that AIE exposure results in reduced expression of the $\delta$-subunit in the adult hippocampus (Centanni et al., 2014), a finding that was consistent with a reduction of tonic currents in the AIE exposed adult hippocampus (Fleming et al., 2012; Fleming et al., 2013). Thus, it was unexpected that we did not observe any significant effect of AIE on either total or surface expression of the $\delta-$ subunit in the mPFC in the present study. Since AIE-induced attenuation of the tonic current was observed only for layer $\mathrm{V}$ pyramidal neurons with no alteration of tonic currents in layers II/III, it is possible that an AIE-induced reduction in $\delta$-subunit expression specifically in layer $\mathrm{V}$ could have been obscured by subunit expression in other layers as a result of the tissue punch procedure that included all cortical layers. However, follow-up immunohistochemistry studies revealed that this did not appear to be the case. An additional caveat to these observations is that since neither the immunoblot nor immunohistochemistry procedures differentiated surface from non-surface receptors, the possibility remained that a reduction in the expression of surface $\mathrm{GABA}_{\mathrm{A}} \mathrm{Rs}$ could have been offset by an increase in their intracellular expression. Once again, follow-up cross-linking studies showed that AIE exposure did not alter the surface expression of $\delta-G_{A B A}$ Rs. Taken together, these data strongly suggest that the AIE-induced reduction in tonic current in the mPFC is not the result of reduced $\delta-G_{A B A} R$ expression but instead may be related to a change in receptor efficacy. Of particular interest are observations that PKA mediated phosphorylation of the $\beta 1$ and $\beta 3$ subunits of $\mathrm{GABA}_{\mathrm{A}} \mathrm{R}$ reduce and increase, respectively, channel conductance without altering surface expression (Brandon et al., 2002). Although speculative, the AIEinduced reduction of tonic current amplitude observed in the present study may relate to either an increase in the basal level of PKA-mediated phosphorylation of $\beta 1$ and/or a decrease in phosphorylation of $\beta 3$ subunits of extrasynaptic $\mathrm{GABA}_{\mathrm{A}} \mathrm{Rs}$. 
There is significant evidence that both ethanol and neurosteroids act as high affinity positive allosteric modulators of $\delta-\mathrm{GABA}_{\mathrm{A}} \mathrm{Rs}$. Our observations of an AIE-induced reduction in the amplitude of the tonic current led us to hypothesize that PrL-C neurons in AIE exposed adult rats would exhibit reduced facilitation in response to acute exposure of either ethanol or neurosteroids. As expected, bath application of ethanol and allopregnanolone resulted in a dose-dependent facilitation of the tonic current. In slices from AIE exposed rats, the amplitude of facilitation of the tonic current by either ethanol or allopregnanolone was significantly reduced. However, expression of these data as a percentage of the amplitude of the THIP-activated tonic current obtained in the respective control and AIE conditions revealed no difference in facilitation by either ethanol or allopregnanolone. These observations indicate that AIE exposure results in reduced efficacy but not affinity of the $\mathrm{GABA}_{\mathrm{A}} \mathrm{R}$ tonic current to facilitation by either ethanol or allopregnanolone. At least in the case of the acute effects of alcohol, these observations are consistent with behavioral studies showing that adolescents are less sensitive to the physiological effects of alcohol when similar doses are administered (Hollstedt et al., 1980a; Hollstedt et al., 1980b; Ramirez and Spear, 2010). In addition, exposure to alcohol during adolescence alters the efficacy of acute ethanol in the adult dentate gyrus of the hippocampus (Fleming et al., 2007). It has been suggested that adolescent alcohol abuse can result in a "lock-in" of certain cellular and behavioral aspects of the adolescent phenotype in the adult (Spear and Swartzwelder, 2014). The results of the present study are in agreement with this construct and further suggest that this lock-in may include reduced GABAergic activity of the adolescent PFC that persists into adulthood.

\section{Supplementary Material}

Refer to Web version on PubMed Central for supplementary material.

\section{Acknowledgments}

This work was funded by NIH grants R01AA010983, R01 AA022701 and U01AA019967 (LJC), K01AA022475 (HTD) and F31AA002843 (SWC), F32AA022836 (EJB). The authors thank Griffin Siegel and Molly McDougle for technical assistance.

\section{References}

Akbarian S, Huntsman MM, Kim JJ, Tafazzoli A, Potkin SG, Bunney WE Jr, Jones EG. GABAA receptor subunit gene expression in human prefrontal cortex: comparison of schizophrenics and controls. Cerebral cortex (New York, NY : 1991). 1995; 5:550-560.

Ben-Ari Y, Gaiarsa JL, Tyzio R, Khazipov R. GABA: a pioneer transmitter that excites immature neurons and generates primitive oscillations. Physiological reviews. 2007; 87:1215-1284. [PubMed: 17928584]

Boutros N, Semenova S, Liu W, Crews FT, Markou A. Adolescent intermittent ethanol exposure is associated with increased risky choice and decreased dopaminergic and cholinergic neuron markers in adult rats. Int $\mathbf{J}$ Neuropsychopharmacol. 2014; 18

Brandon N, Jovanovic J, Moss S. Multiple roles of protein kinases in the modulation of gammaaminobutyric acid(A) receptor function and cell surface expression. Pharmacology \& therapeutics. 2002; 94:113-122. [PubMed: 12191597]

Breese GR, Criswell HE, Carta M, Dodson PD, Hanchar HJ, Khisti RT, Mameli M, Ming Z, Morrow AL, Olsen RW, Otis TS, Parsons LH, Penland SN, Roberto M, Siggins GR, Valenzuela CF, Wallner 
M. Basis of the gabamimetic profile of ethanol. Alcohol Clin Exp Res. 2006; 30:731-744. [PubMed: 16573592]

Cagetti E, Liang J, Spigelman I, Olsen RW. Withdrawal from chronic intermittent ethanol treatment changes subunit composition, reduces synaptic function, and decreases behavioral responses to positive allosteric modulators of GABAA receptors. Mol Pharmacol. 2003; 63:53-64. [PubMed: 12488536]

Casey BJ, Jones RM. Neurobiology of the adolescent brain and behavior: implications for substance use disorders. Journal of the American Academy of Child and Adolescent Psychiatry. 2010; 49:1189-1201. [PubMed: 21093769]

Centanni SW, Teppen T, Risher ML, Fleming RL, Moss JL, Acheson SK, Mulholland PJ, Pandey SC, Chandler LJ, Swartzwelder HS. Adolescent alcohol exposure alters GABAA receptor subunit expression in adult hippocampus. Alcohol Clin Exp Res. 2014; 38:2800-2808. [PubMed: 25421517]

Clark JJ, Nasrallah NA, Hart AS, Collins AL, Bernstein IL, Phillips PE. Altered risk-based decision making following adolescent alcohol use results from an imbalance in reinforcement learning in rats. PLoS One. 2012; 7:e37357. [PubMed: 22615989]

Cramer NP, Best TK, Stoffel M, Siarey RJ, Galdzicki Z. GABAB-GIRK2-mediated signaling in Down syndrome. Advances in pharmacology (San Diego, Calif). 2010; 58:397-426.

Datta D, Arion D, Lewis DA. Developmental Expression Patterns of GABAA Receptor Subunits in Layer 3 and 5 Pyramidal Cells of Monkey Prefrontal Cortex. Cerebral cortex (New York, NY : 1991). 2014

De Bellis MD, Narasimhan A, Thatcher DL, Keshavan MS, Soloff P, Clark DB. Prefrontal cortex, thalamus, and cerebellar volumes in adolescents and young adults with adolescent-onset alcohol use disorders and comorbid mental disorders. Alcohol Clin Exp Res. 2005; 29:1590-1600. [PubMed: 16205359]

Drasbek KR, Jensen K. THIP, a hypnotic and antinociceptive drug, enhances an extrasynaptic GABAA receptor-mediated conductance in mouse neocortex. Cerebral cortex (New York, NY : 1991). 2006; 16:1134-1141.

Egawa K, Fukuda A. Pathophysiological power of improper tonic GABA(A) conductances in mature and immature models. Frontiers in neural circuits. 2013; 7:170. [PubMed: 24167475]

Farrant M, Nusser Z. Variations on an inhibitory theme: phasic and tonic activation of GABA(A) receptors. Nature reviews Neuroscience. 2005; 6:215-229. [PubMed: 15738957]

Fleming RL, Acheson SK, Moore SD, Wilson WA, Swartzwelder HS. In the rat, chronic intermittent ethanol exposure during adolescence alters the ethanol sensitivity of tonic inhibition in adulthood. Alcohol Clin Exp Res. 2012; 36:279-285. [PubMed: 22014205]

Fleming RL, Li Q, Risher ML, Sexton HG, Moore SD, Wilson WA, Acheson SK, Swartzwelder HS. Binge-Pattern Ethanol Exposure During Adolescence, but Not Adulthood, Causes Persistent Changes in GABA(A) Receptor-Mediated Tonic Inhibition in Dentate Granule Cells. Alcohol Clin Exp Res. 2013

Fleming RL, Wilson WA, Swartzwelder HS. Magnitude and ethanol sensitivity of tonic GABAA receptor-mediated inhibition in dentate gyrus changes from adolescence to adulthood. Journal of neurophysiology. 2007; 97:3806-3811. [PubMed: 17376852]

Gass JT, Glen WB Jr, McGonigal JT, Trantham-Davidson H, Lopez MF, Randall PK, Yaxley R, Floresco SB, Chandler LJ. Adolescent alcohol exposure reduces behavioral flexibility, promotes disinhibition, and increases resistance to extinction of ethanol self-administration in adulthood. Neuropsychopharmacology. 2014; 39:2570-2583. [PubMed: 24820536]

Gill KM, Grace AA. The role of alpha5 GABAA receptor agonists in the treatment of cognitive deficits in schizophrenia. Curr Pharm Des. 2014; 20:5069-5076. [PubMed: 24345268]

Grosshans DR, Clayton DA, Coultrap SJ, Browning MD. Analysis of glutamate receptor surface expression in acute hippocampal slices. Science's STKE : signal transduction knowledge environment. 2002; 2002:8.

Hashimoto T, Arion D, Unger T, Maldonado-Aviles JG, Morris HM, Volk DW, Mirnics K, Lewis DA. Alterations in GABA-related transcriptome in the dorsolateral prefrontal cortex of subjects with schizophrenia. Molecular psychiatry. 2008; 13:147-161. [PubMed: 17471287] 
Hines RM, Davies PA, Moss SJ, Maguire J. Functional regulation of GABAA receptors in nervous system pathologies. Current opinion in neurobiology. 2012; 22:552-558. [PubMed: 22036769]

Hoftman GD, Lewis DA. Postnatal developmental trajectories of neural circuits in the primate prefrontal cortex: identifying sensitive periods for vulnerability to schizophrenia. Schizophrenia bulletin. 2011; 37:493-503. [PubMed: 21505116]

Hollstedt C, Olsson O, Rydberg U. Effects of ethanol on the developing rat. II. Coordination as measured by the tilting-plane test. Medical biology. 1980a; 58:164-168. [PubMed: 7253727]

Hollstedt C, Rydberg U, Olsson O, Buijten J. Effects of ethanol on the developing rat. I. Ethanol metabolism and effects on lactate, pyruvate, and glucose concentrations. Medical biology. 1980b; 58:158-163. [PubMed: 7253726]

LeBlanc JJ, Fagiolini M. Autism: a “critical period” disorder? Neural plasticity. 2011; 2011:921680. [PubMed: 21826280]

Liang J, Lindemeyer AK, Suryanarayanan A, Meyer EM, Marty VN, Ahmad SO, Shao XM, Olsen RW, Spigelman I. Plasticity of GABA(A) receptor-mediated neurotransmission in the nucleus accumbens of alcohol-dependent rats. Journal of neurophysiology. 2014; 112:39-50. [PubMed: 24694935]

Liang J, Suryanarayanan A, Abriam A, Snyder B, Olsen RW, Spigelman I. Mechanisms of reversible GABAA receptor plasticity after ethanol intoxication. J Neurosci. 2007; 27:12367-12377. [PubMed: 17989301]

Liang J, Zhang N, Cagetti E, Houser CR, Olsen RW, Spigelman I. Chronic intermittent ethanolinduced switch of ethanol actions from extrasynaptic to synaptic hippocampal GABAA receptors. J Neurosci. 2006; 26:1749-1758. [PubMed: 16467523]

Lindemeyer AK, Liang J, Marty VN, Meyer EM, Suryanarayanan A, Olsen RW, Spigelman I. Ethanolinduced plasticity of GABAA receptors in the basolateral amygdala. Neurochemical research. 2014; 39:1162-1170. [PubMed: 24710789]

Mejia-Toiber J, Boutros N, Markou A, Semenova S. Impulsive choice and anxiety-like behavior in adult rats exposed to chronic intermittent ethanol during adolescence and adulthood. Behavioural brain research. 2014; 266:19-28. [PubMed: 24566059]

Moss SJ, Smart TG. Constructing inhibitory synapses. Nature reviews Neuroscience. 2001; 2:240-250. [PubMed: 11283747]

Pirker S, Schwarzer C, Wieselthaler A, Sieghart W, Sperk G. GABA(A) receptors: immunocytochemical distribution of 13 subunits in the adult rat brain. Neuroscience. 2000; 101:815-850. [PubMed: 11113332]

Ramirez RL, Spear LP. Ontogeny of ethanol-induced motor impairment following acute ethanol: assessment via the negative geotaxis reflex in adolescent and adult rats. Pharmacology, biochemistry, and behavior. 2010; 95:242-248.

Schindler AG, Tsutsui KT, Clark JJ. Chronic alcohol intake during adolescence, but not adulthood, promotes persistent deficits in risk-based decision making. Alcohol Clin Exp Res. 2014; 38:16221629. [PubMed: 24689661]

Spear LP. Modeling adolescent development and alcohol use in animals. Alcohol research \& health : the journal of the National Institute on Alcohol Abuse and Alcoholism. 2000; 24:115-123. [PubMed: 11199278]

Spear LP, Swartzwelder HS. Adolescent alcohol exposure and persistence of adolescent-typical phenotypes into adulthood: A mini-review. Neuroscience and biobehavioral reviews. 2014; 45c:18. [PubMed: 24813805]

Squeglia LM, Pulido C, Wetherill RR, Jacobus J, Brown GG, Tapert SF. Brain response to working memory over three years of adolescence: influence of initiating heavy drinking. Journal of studies on alcohol and drugs. 2012; 73:749-760. [PubMed: 22846239]

Squeglia LM, Rinker DA, Bartsch H, Castro N, Chung Y, Dale AM, Jernigan TL, Tapert SF. Brain volume reductions in adolescent heavy drinkers. Dev Cogn Neurosci. 2014; 9:117-125. [PubMed: 24632141]

Squeglia LM, Spadoni AD, Infante MA, Myers MG, Tapert SF. Initiating moderate to heavy alcohol use predicts changes in neuropsychological functioning for adolescent girls and boys. Psychol Addict Behav. 2009; 23:715-722. [PubMed: 20025379] 
Sundstrom-Poromaa I, Smith DH, Gong QH, Sabado TN, Li X, Light A, Wiedmann M, Williams K, Smith SS. Hormonally regulated alpha(4)beta(2)delta GABA(A) receptors are a target for alcohol. Nature neuroscience. 2002; 5:721-722. [PubMed: 12118257]

Tabuchi K, Blundell J, Etherton MR, Hammer RE, Liu X, Powell CM, Sudhof TC. A neuroligin-3 mutation implicated in autism increases inhibitory synaptic transmission in mice. Science. 2007; 318:71-76. [PubMed: 17823315]

Trantham-Davidson H, Burnett EJ, Gass JT, Lopez MF, Mulholland PJ, Centanni SW, Floresco SB, Chandler LJ. Chronic alcohol disrupts dopamine receptor activity and the cognitive function of the medial prefrontal cortex. J Neurosci. 2014; 34:3706-3718. [PubMed: 24599469]

Wallner M, Hanchar HJ, Olsen RW. Ethanol enhances alpha 4 beta 3 delta and alpha 6 beta 3 delta gamma-aminobutyric acid type A receptors at low concentrations known to affect humans. Proc Natl Acad Sci U S A. 2003; 100:15218-15223. [PubMed: 14625373]

Wang DD, Kriegstein AR. Defining the role of GABA in cortical development. The Journal of physiology. 2009; 587:1873-1879. [PubMed: 19153158]

Weitlauf C, Woodward JJ. Ethanol selectively attenuates NMDAR-mediated synaptic transmission in the prefrontal cortex. Alcohol Clin Exp Res. 2008; 32:690-698. [PubMed: 18341645]

Whissell PD, Lecker I, Wang DS, Yu J, Orser BA. Altered expression of deltaGABAA receptors in health and disease. Neuropharmacology. 2015; 88:24-35. [PubMed: 25128850]

Zheleznova NN, Sedelnikova A, Weiss DS. Function and modulation of delta-containing GABA(A) receptors. Psychoneuroendocrinology 34 Suppl. 2009; 1:S67-73. 


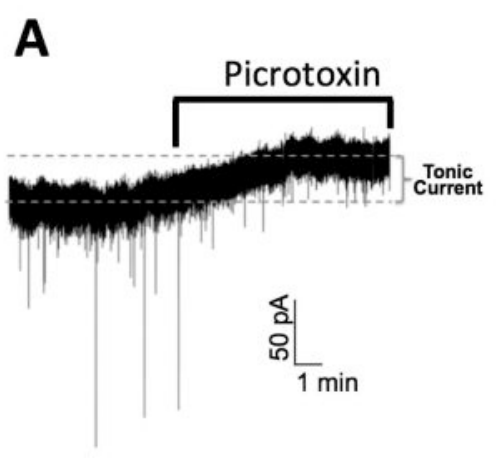

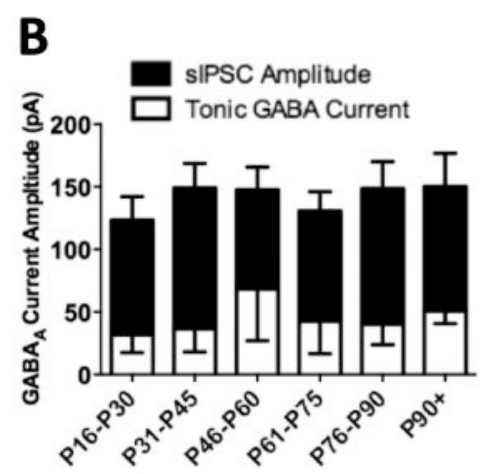

Postnatal age (days)

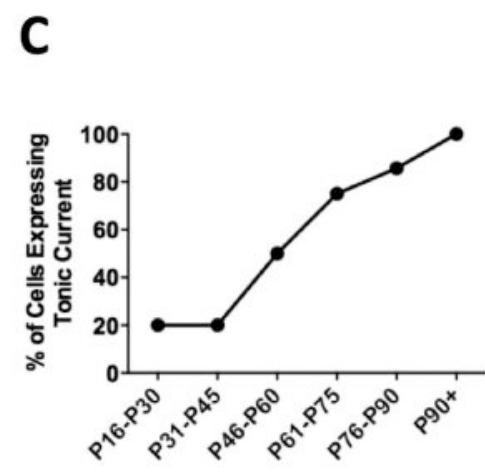

Postnatal age (days)

Figure 1. Expression of the $\mathrm{GABA}_{\mathrm{A}} \mathrm{R}$ tonic current is developmentally regulated in layer $\mathrm{V}$ pyramidal neurons of the PrL-C

A) Representative trace showing the measurement of tonic current as a change in holding current $\left(\mathrm{I}_{\text {hold }}\right)$ after bath application of the $\mathrm{GABA}_{\mathrm{A}} \mathrm{R}$ antagonist picrotoxin $(100 \mu \mathrm{M}$, gray dashed line). B) Phasic (black) and tonic (white) $\mathrm{GABA}_{\mathrm{A}} \mathrm{R}$ currents measured at specific developmental time-points (PD: postnatal day) revealed that the amplitude of both tonic and phasic GABA currents remained stable throughout development. C) Although there was no developmental change in tonic current amplitude, the percentage of cells expressing a tonic current exhibited a dramatic developmental increase $(p=0.002)$. 


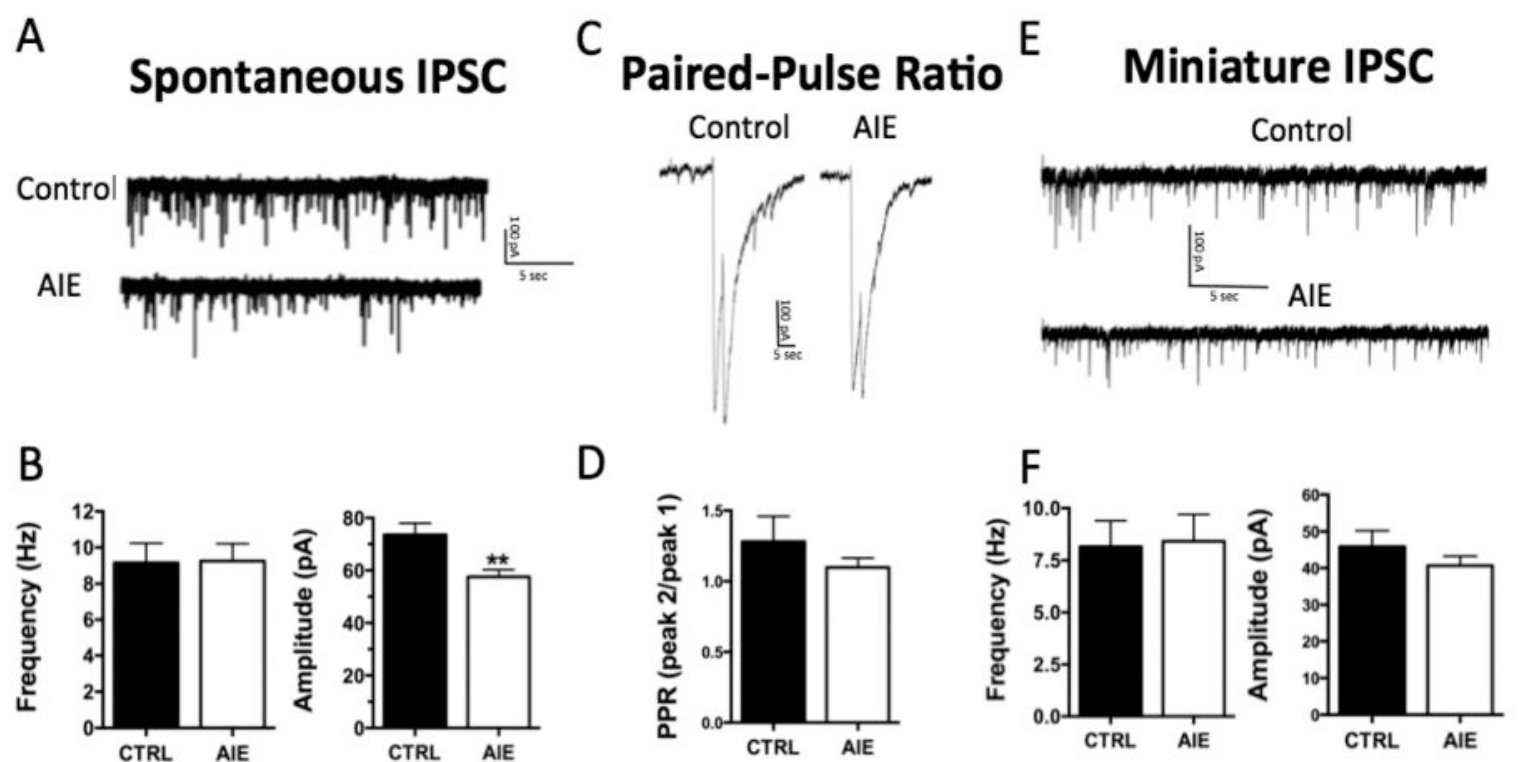

Figure 2. Effect of adolescent ethanol exposure on phasic GABA $A_{A} R$ currents in layer $V$ pyramidal neurons of the adult PrL-C

A) Representative traces of IPSCs from adult PrL-C slice obtained from control and AIE exposed rats. Cells were voltage-clamped at $-70 \mathrm{mV}$. B) While the frequency was similar in slices from both control and AIE treated rats, spontaneous IPSC (sIPSC) amplitude was significantly reduced in slices from AIE exposed rats $(\mathrm{n}=20-21$ cells/group; $* * p=0.004)$.

C) Representative paired-pulse traces of evoked IPSC (eIPSC) currents from adult PrL-C slices obtained from control and AIE treated rats. D) The paired-pulse ratio (PPR) was not altered by AIE exposure ( $\mathrm{n}=8-9$ cells/group). E) Representative traces of miniature IPSCs (mIPSC) from adult PrL-C slices obtained from control and AIE exposure rats. F) AIE did not alter either the amplitude or frequency of mIPSCs ( $n=8-9$ cells/group). 
A

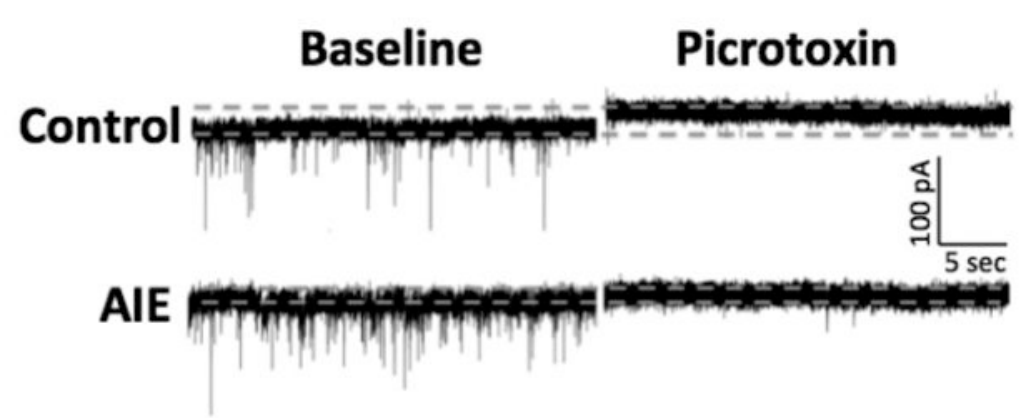

B

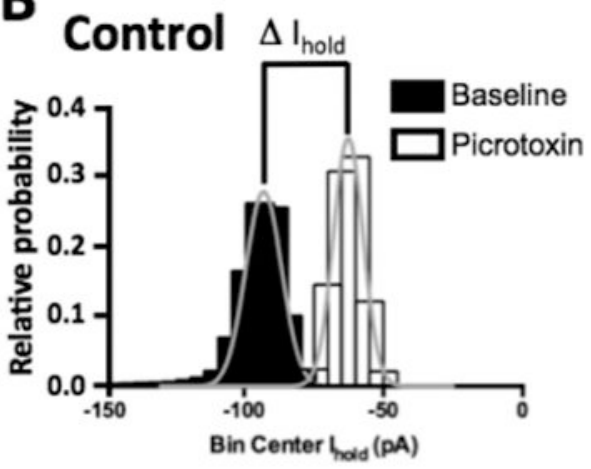

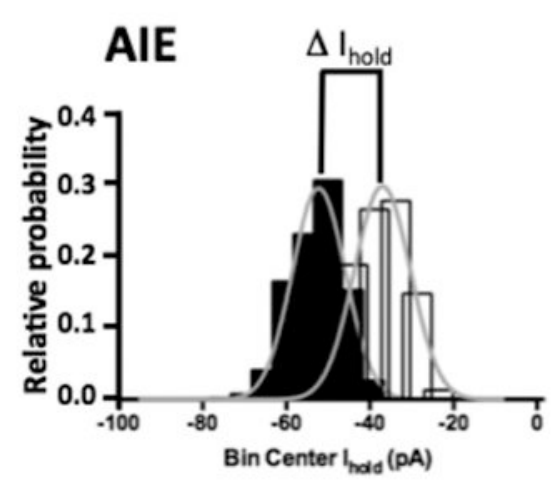

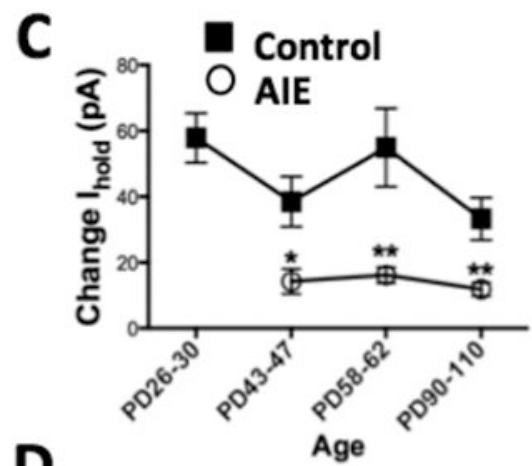

D

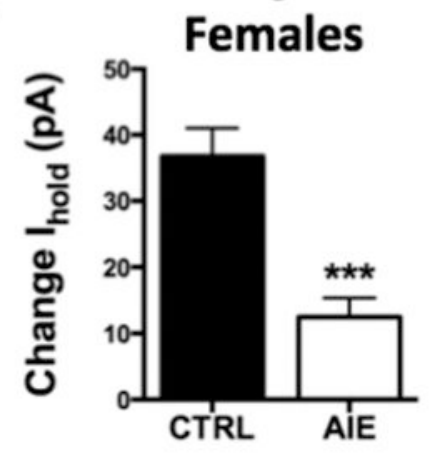

Figure 3. Adolescent ethanol exposure results in a reduction in the amplitude of the $G A B A_{A} R$ tonic current

A) Representative trace showing tonic $\mathrm{GABA}_{\mathrm{A}} \mathrm{R}$ current, measured as the magnitude of change in holding current after bath application of the $\mathrm{GABA}_{\mathrm{A}} \mathrm{R}$ antagonist picrotoxin (100 $\mu \mathrm{M})$, in PrL-C slices obtained from control and AIE exposed rats. B) Representative allpoint histograms and fitted Gaussian functions for the whole-cell current data showing the peak $\mathrm{I}_{\text {hold }}$ before and after picrotoxin in slices from control (left panel) and AIE (middle panel) rats. C) Slices obtained from control rats revealed that the amplitude of the tonic $\mathrm{GABA}_{\mathrm{A}} \mathrm{R}$ current remained stable throughout development and AIE exposure significantly attenuated tonic GABA current at all time-points examined, including shortly after exposure (PD $45 \pm 3$ days; $\mathrm{n}=5-6$ cells/group; $* p<0.05$ ), in early adulthood (PD $60 \pm 3$ days; $\mathrm{n}=$ $6-8$ cells/group; $* * p<0.01$ ), and in the fully mature adult (PD90 \pm 6 days; $\mathrm{n}=8-10$ cells/ group; $* * p<0.01)$. D) AIE exposure significantly attenuated tonic GABA current in layer V pyramidal neurons from adult female rats $(\mathrm{n}=7-8$ cells/group, $* * * p<0.001)$. 


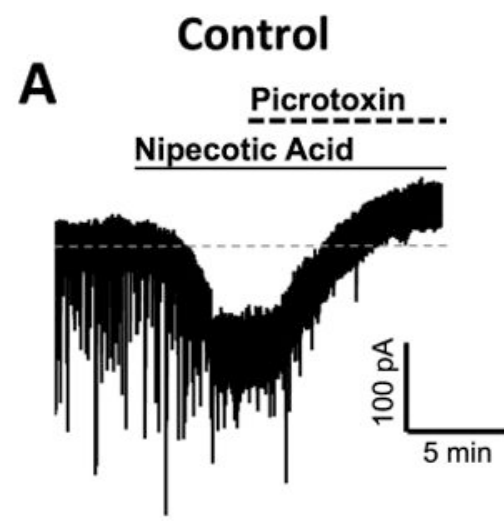

B
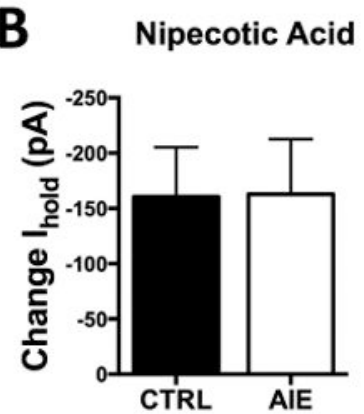

AIE

Picrotoxin

Nipecotic Acid

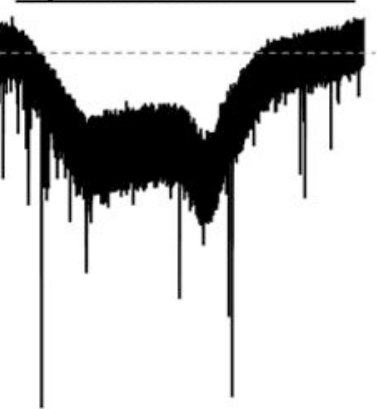

Nip Acid + Picro

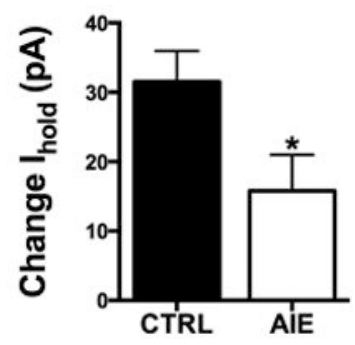

Figure 4. Blocking GABA reuptake does not reverse AIE-associated reduction in tonic $G_{A B A} R$ currents

A) Representative trace showing changes in holding current that occur following bath application of nipecotic acid in slices from the adult PrL-C. After establishing a stable baseline holding current, nipecotic acid $(500 \mu \mathrm{M})$ was bath applied for 5 minutes. Next, picrotoxin $(100 \mu \mathrm{M})$ was also added to the bath. The tonic current was measured as the change in $\mathrm{I}_{\text {hold }}$ from baseline (gray line) to that observed after picrotoxin. B) AIE exposure resulted in a significant decrease in the amplitude of the $\mathrm{GABA}_{\mathrm{A}} \mathrm{R}$ tonic current amplitude compared to slices from control rats $\left(\mathrm{n}=6-7\right.$ cells/group; $\left.{ }^{*} p<0.05\right)$. 
A

\section{Control}

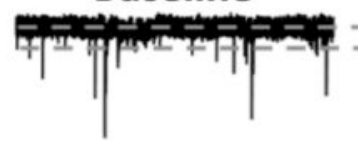

AIE

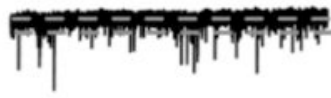

B

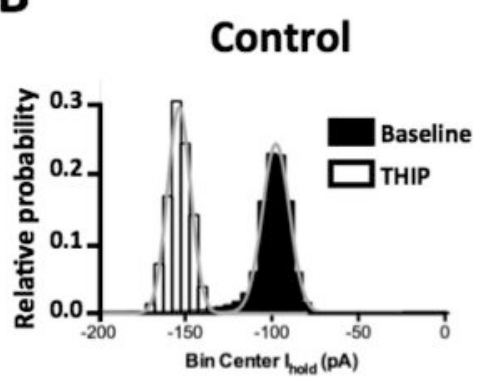

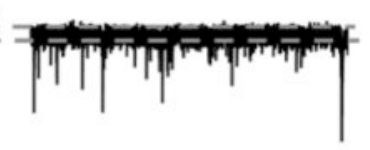

THIP
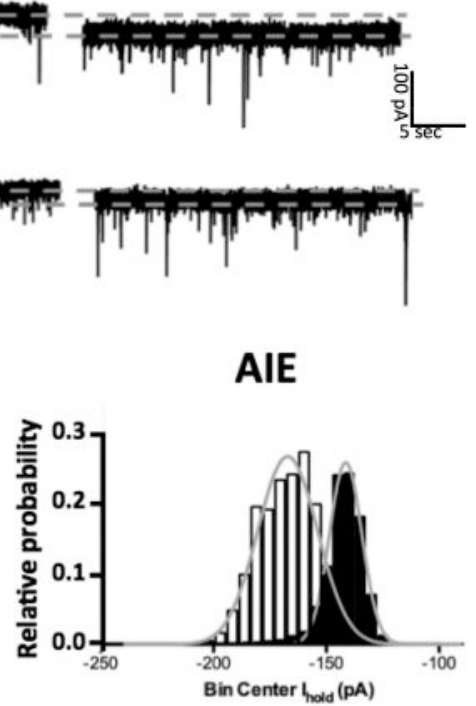

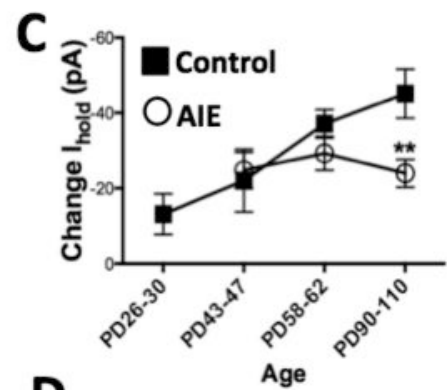

D

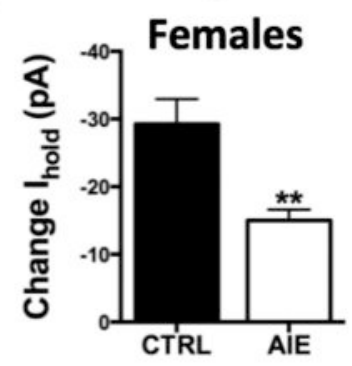

Figure 5. The decrease in the tonic $G_{B B A} R$ current following adolescent ethanol exposure reflects attenuation of current mediated by $\delta$-subunit containing receptors

A) Representative trace showing the effect of bath application of the selective $\delta-G A B A_{A} R$ agonist THIP. B) Representative all-point histogram and Gaussian function that were used to measure the effect of THIP as a change in the $\mathrm{I}_{\text {hold }}$ for each individual cell. C) THIPmediated change in the $\mathrm{I}_{\text {hold }}$ in PrL-C slices obtained from control and AIE exposed rats at different developmental ages. In slices obtained prior to initiation of AIE exposure (PD28, $n$ $=5$ cells/group), shortly after the last cycle of AIE exposure (PD45, $\mathrm{n}=5$ cells/group), and in early adulthood (PD60, $\mathrm{n}=7$ cells/group) there were no differences in THIP modulation of holding current. However, in slices from adult rats, there was a significant reduction in the THIP mediated current $\left(\mathrm{n}=9-10\right.$ cells/group, $\left.{ }^{*} p=0.04\right)$. D) AIE exposure significantly attenuated THIP-mediated current in layer V pyramidal neurons from adult female rats $(\mathrm{n}=$ $6-9$ cells/group $* * p<0.01)$. 
A

C

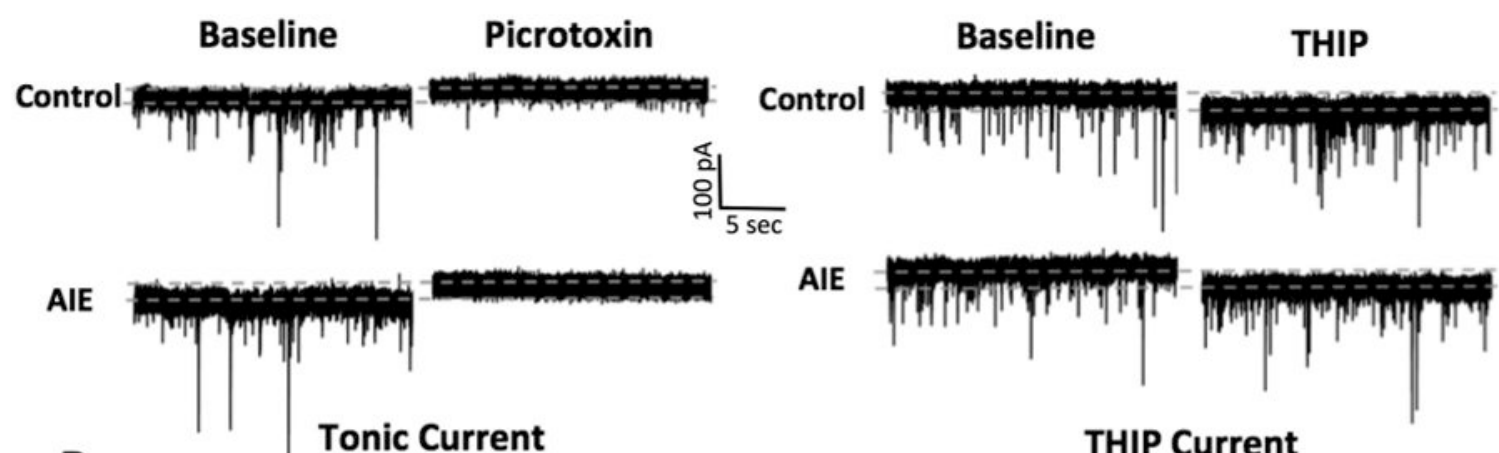

B

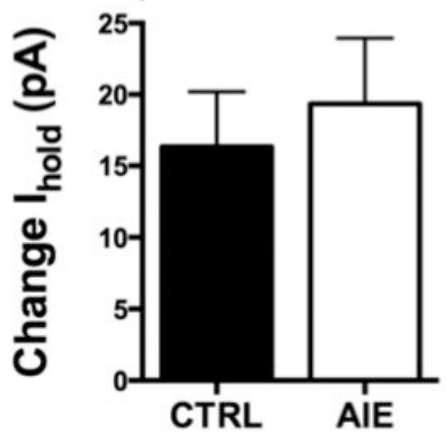

D

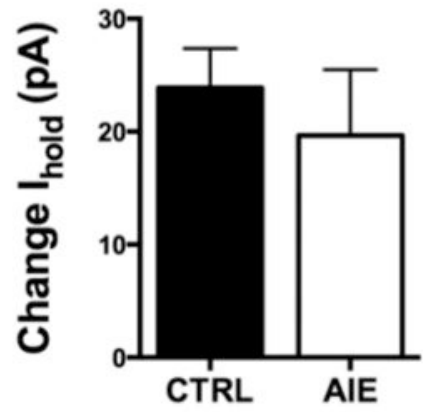

Figure 6. Adolescent ethanol exposure has no effect on the tonic GABA $\mathrm{A}$ current of pyramidal neurons in layer II/III of the adult PrL-C

A) Representative traces showing the effect of picrotoxin $(100 \mu \mathrm{M})$ on $\mathrm{GABA}_{\mathrm{A}} \mathrm{R}$ tonic currents in layer II/III pyramidal neurons. B) AIE had no effect on picrotoxin-sensitive $\mathrm{GABA}_{\mathrm{A}} \mathrm{R}$ tonic current in pyramidal neurons of layer II/III ( $\mathrm{n}=4-6$ cells/group). C) Representative traces showing current mediated by $\delta$-subunit containing $\mathrm{GABA}_{\mathrm{A}} \mathrm{R}$ receptors in layer II/III pyramidal neurons measured using the $\delta-\mathrm{GABA}_{\mathrm{A}} \mathrm{R}$ agonist THIP $(1 \mu \mathrm{M})$. D) THIP-mediated changes in the holding current revealed that AIE had no effect on $\delta$ $\mathrm{GABA}_{\mathrm{A}} \mathrm{R}$ current amplitude in layer II/III of PrL-C ( $n=5-6$ cells/group). 

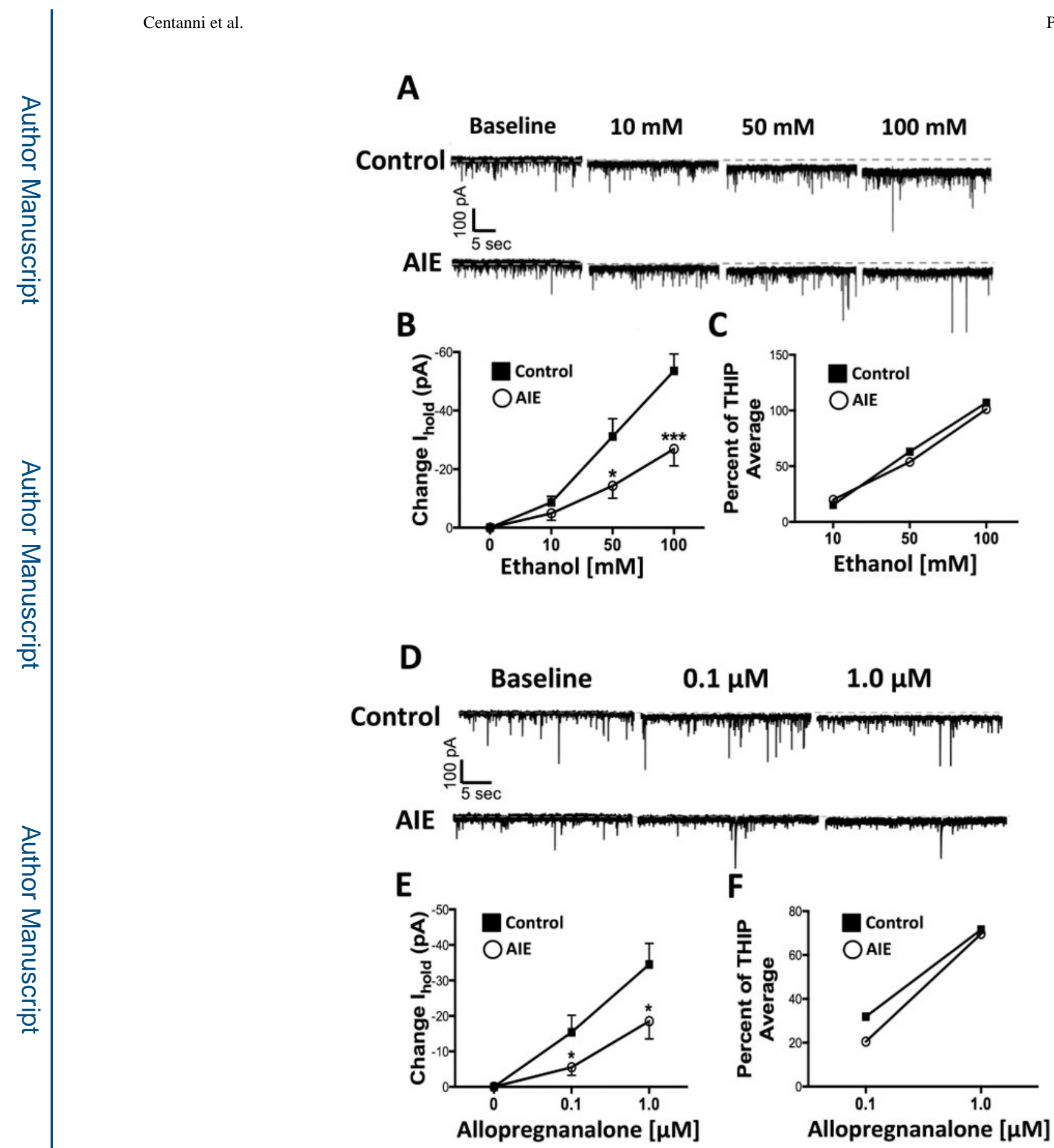

Figure 7. Adolescent ethanol exposure significantly decreases ethanol and allopregnanoloneinduced facilitation of the tonic GABA $\mathbf{A}$ current in adult PrL-C

A) Representative traces showing the change in $\mathrm{I}_{\text {hold }}$ in layer $\mathrm{V}$ pyramidal neurons in response to bath application of ethanol $(10 \mathrm{mM}, 50 \mathrm{mM}$ and $100 \mathrm{mM})$ in PrL-C slices obtained from control and AIE exposed rats. B) Bath application of ethanol resulted in a dose-dependent facilitation of the tonic current, especially at higher doses $(n=15$ cells/dose, $p<0.0001$ ). The enhancement of tonic current that occurred with bath application of 50 and $100 \mathrm{mM}$ ethanol was significantly attenuated in slices obtained from AIE exposed rats 
compared to slices from control rats $\left(\mathrm{n}=6-10\right.$ cells/group for each dose; ${ }^{*} \mathrm{p}<0.05,{ }^{* * *} p<$ 0.001). C) Comparison of ethanol facilitation of the tonic current to the average THIP current in control and AIE exposed conditions indicates that AIE did not alter the affinity of the $\delta-\mathrm{GABA}_{\mathrm{A}} \mathrm{R}$ to acute alcohol and instead reduced the efficacy of facilitation of tonic currents. D) Representative traces showing the change in $\mathrm{I}_{\text {hold }}$ in layer $\mathrm{V}$ pyramidal neurons in response to bath application of a low $(0.1 \mu \mathrm{M})$ and high $(1.0 \mu \mathrm{M})$ dose of the allopregnanolone in PrL-C slices obtained from control and AIE exposed adult rats E) Allopregnanolone dose-dependently facilitated the tonic current ( $\mathrm{n}=18$ cells/dose, $p=$ 0.0009), and this enhancement was significantly attenuated in slices obtained from AIE exposed rats compared to slices from control rats $\left(\mathrm{n}=8-9\right.$ cells/group for each dose, ${ }^{*} p<$ 0.05). F) Comparison of allopregnanolone facilitation of the tonic current to the average THIP current in control and AIE exposed conditions indicates that AIE did not alter the affinity of the $\delta-\mathrm{GABA}_{\mathrm{A}} \mathrm{R}$ tonic current to acute allopregnanolone and instead reduced the efficacy of facilitation. 
A

$\begin{array}{lllll}\alpha 1 & \alpha 4 & \alpha 5 & \delta & \gamma 2\end{array}$

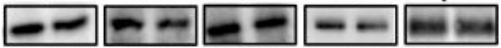

Ctrl AIE Ctrl AIE Ctrl AIE Ctrl AIE Ctrl AIE

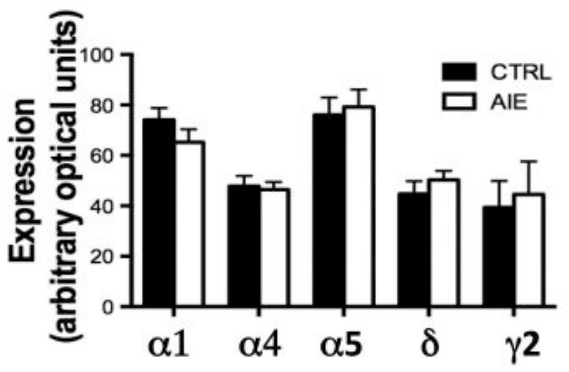

C

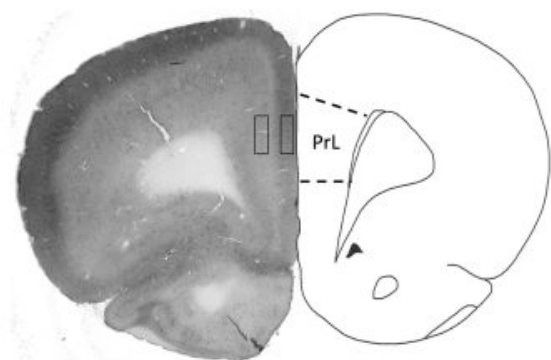

B

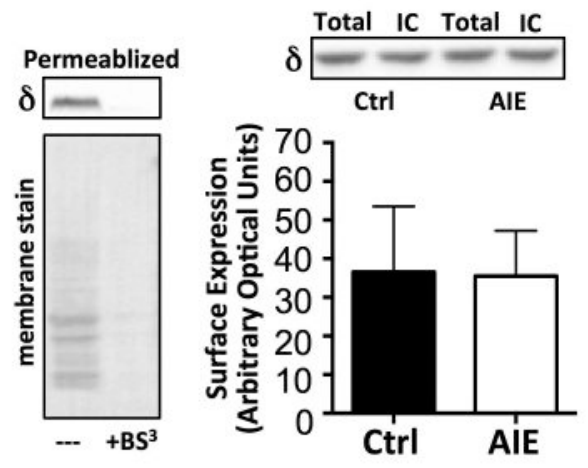

D

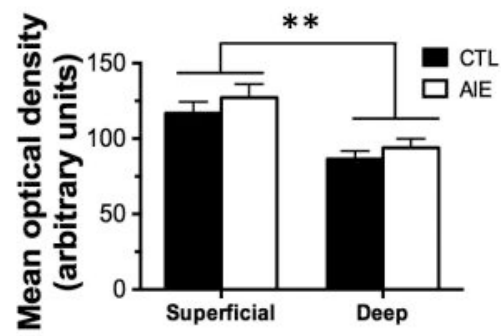

Figure 8. Adolescent ethanol exposure has no effect on expression of $G A B A_{A} R$ subunits that contribute to the tonic current

A) Protein expression of $\mathrm{GABA}_{\mathrm{A}} \mathrm{R}$ subunit in the PrL-C of AIE exposed adult rats measured in total tissue extracts $\left(n=8-9\right.$ rats/group). B) Surface expression of $\delta-G A B A_{A} R_{s}$ using $B S^{3}$ cross-linking of surface membrane proteins in acute slices. Shown on the left is loss of the $\delta$ subunit and total protein upon detergent permeabilization of the slice in the presence and absence of the cross-linking reagent $\mathrm{BS}^{3}$. Shown on the right is quantification of $\delta$-subunit surface expression expressed as the difference between the non-cross-linked intracellular and the total subunit expression ( $n=13-14$ rats/group). C) Representative image from an Air exposed control rat of immunohistochemical labeling for the $\delta$-subunit showing differential expression in superficial and deep layers of the cortex. D) Quantification of the boxed area in $\mathrm{C}$ revealed significantly greater $\delta$-subunit expression in superficial versus deep layers of the PrL-C $(p<0.001)$ but a significant effect of AIE exposure was not observed. 